\title{
ASSOCIATION OF THE APOLIPOPROTEIN E4 ALLELE WITH HYPERCHOLESTEROLEMIA IN APPARENTLY HEALTHY MALE ADULTS IN TOKYO
}

\author{
Shigeru Tsuchiya, ${ }^{1}$ Yasuko Yamanouchi, ${ }^{2}$ Ryunosuke MrYaZaKI, ${ }^{3}$ \\ Hisako Yanagi, ${ }^{2}$ Kimiko Yamakawa, ${ }^{2}$ Kenji Yuzawa, ${ }^{2}$ \\ Minoru OHNUKI, ${ }^{1}$ and Hideo HaMAGUCHI ${ }^{2}$ \\ ${ }^{1}$ Institute of Community Medicine and ${ }^{2}$ Institute of Basic Medical Sciences, \\ University of Tsukuba, Tsukuba 305, Japan \\ ${ }^{3}$ Kudanzaka-Hospital, Chiyoda-ku, Tokyo 102, Japan
}

\begin{abstract}
Summary This study was performed to investigate whether the apolipoprotein (apo) EA allele is associated with hypercholesterolemia in Japanese male adults in large cities. The apo $\mathrm{E}$ phenotypes and serum lipid levels were analyzed on 142 apparently healthy male civil servants working in Tokyo. The prevalence of hypercholesterolemia (serum total cholesterol level $>250 \mathrm{mg} / \mathrm{dl}$ ) were $4.7 \%$ in 106 apo E4-absent subjects and $19.4 \%$ in 36 apo E4-present subjects $(\mathrm{p}=0.012)$. The prevalence of hypercholesterolemia were $5.3 \%$ in 94 subjects with the apo E3/3 phenotype and $20.0 \%$ in 30 subjects with the apo $E 3 / 4$ phenotype $(p=0.023)$. In addition, mean serum total cholesterol levels were significantly higher in the apo E4-present subjects than in the apo E4-absent subjects $(213 \pm 29.1$ versus $199 \pm 36.0$, $\mathrm{p}<0.05$ ). The data suggest that the apo E4 allele is associated with hypercholesterolemia in Japanese male adults working in large cities.
\end{abstract}

\section{INTRODUCTION}

Human apolipoprotein (apo) $\mathrm{E}$ is a single chain of 299 amino acids and a major protein constituent of plasma very low density lipoprotein (VLDL) (Shelburne and Quarfordt, 1974; Rall et al., 1982). Apo E is also of a normal protein constituent of chyromicron remnants, intermediate density lipoproteins, and a subfraction of the high density lipoproteins (Weisgraber and Mahley, 1978; Mahley and Innerarity, 1983). Apo $\mathrm{E}$ serves as a mediator of the cellular uptake of specific plasma lipoproteins through an interaction with apo $\mathrm{E}$ receptor and apo B,E receptor (Mahley and Innerarity, 1983). In addition, apo $\mathrm{E}$ is involved in the conversion of VLDL to the low density lipoprotein (LDL) (Ehnholm et al., 1984). In the apo E gene,

Received July 30, 1987; Accepted September 17, 1987 
there are three common alleles, designated $\varepsilon 2, \varepsilon 3$ and $\varepsilon 4$, which code for apo E2, apo E3, and E4, respectively (Zannis et al., 1982). The apo E3 allele is the most common and the apo E4 allele is the second commonest in Japanese (Asakawa et al., 1985; Tsuchiya et al., 1985; Eto et al., 1986). The apo E4 allele is present in about $20 \%$ of populations. Besides the evidence for the association of the apo E2 allele with type III hyperlipoproteinemia (Havel, 1982), there is growing evidence that the apo E4 allele is involved in predisposing one to hyperlipidemia (Assmann et al., 1984; Utermann et al., 1984; Leren et al., 1985; Sing and Davignon, 1985; Tsuchiya et al., 1986; Boerwinkle et al., 1987; Ordovas et al., 1987; Pagnan et al., 1987). In addition, an association of the apo E4 allele with hypercholesterolemia has been demonstrated in Caucasian populations (Utermann et al., 1984; Leren et al., 1985). The purpose of this study is to investigate whether the apo E4 allele is associated with hypercholesterolemia in Japanese male adults working in large cities.

\section{MATERIALS AND METHODS}

The subjects were 142 apparently healthy Japanese male civil servants working in Tokyo. They were selected consecutively from those who visited the health care center of Kudanzaka Hospital, Tokyo, for their annual health examinations. The subjects were not excluded by any other criterion except those with diabetes mellitus, abnormal thyroid function or abnormal kidney function. They ranged in age from 36 to 64 years with an average age of 46.7 years. No individuals indicated use of antihyperlipidemic drugs.

Blood samples were obtained after an overnight fast. The phenotype of apo $E$ was determined by two-dimensional gel electrophoresis as described previously (Tsuchiya et al., 1985). Serum total cholesterol and triglyceride were measured enzymatically (Allain et al., 1974; Sampson et al., 1975) on an automated analyzer (Hitachi Model 712, Hitachi Ltd., Tokyo). HDL cholesterol was determined after isolating the HDL fraction by the dextran sulphate-magnesium chloride precipitation (Kostner, 1976). Statistical differences in the prevalence of hypercholesterolemia were assessed by the Fisher's exact test. Statistical differences in mean serum total cholesterol levels were assessed by the unpaired Student $t$-test (Armitage, 1977).

\section{RESULTS}

Two-dimensional electrophoresis patterns of three common apo $E$ phenotypes are shown in Fig. 1. Table 1 presents the apo $E$ phenotype frequencies, average serum lipid levels, and prevalence of hypercholesterolemia (serum total cholesterol $>$ $250 \mathrm{mg} / \mathrm{dl}$ ) in the samples of 142 unrelated males. Besides three common genetic types of apo E, that is, apo E2, apo E3 and apo E4, apo E5 was detected in one subject and apo E7 in another one subject. The observed phenotype frequencies did not differ from those expected based on Hardy-Weinberg equilibrium. Hypercholes- 

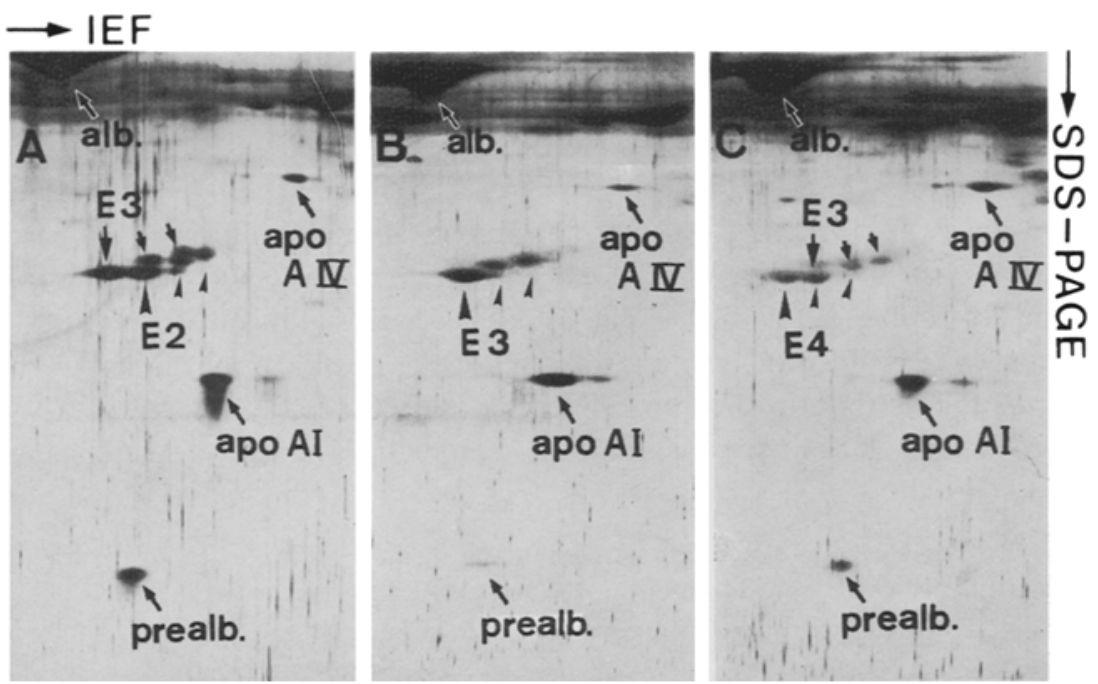

Fig. 1. Three common phenotypes of apo $\mathrm{E}$ in the two-dimensional electrophoresis pattern. A: Apo E2/3, B: Apo E3/3, C: Apo E3/4. E2, E3, and E4 indicate apo E2, apo E3 and apo E4, respectively. Albumin (alb), prealbumin (prealb), apoJipoprotein AI (apo AI), and apolipoprotein AIV (apo AIV) are also shown. Isoelectric forcusing (IEF) was from left to right, and molecular weight separation by SDS-polyacrylamide gel electrophoresis (SDS-PAGE) was from top to bottom.

Table 1. Apo E phenotype distribution, serum lipid levels, and prevalence of hypercholesterolemia.

\begin{tabular}{cccccccc}
\hline $\begin{array}{c}\text { Apo } \mathrm{E} \\
\text { phenotype }\end{array}$ & $\mathrm{n}(\%)$ & $\begin{array}{c}\text { Age } \\
(\mathrm{m} \text { ean } \pm \mathrm{SD})\end{array}$ & $\begin{array}{c}\text { Total Ch } \\
(\mathrm{mg} / \mathrm{d})\end{array}$ & $\begin{array}{c}\text { Total TG } \\
(\mathrm{mg} / \mathrm{dl})\end{array}$ & \multicolumn{2}{c}{$\mathrm{HCH}$} \\
\hline $\mathrm{E} 3 / 3$ & 94 & $(66.2)$ & $47 \pm 6.8$ & $198 \pm 29.6$ & $127 \pm 76.5$ & 5 & $(5.3)$ \\
$\mathrm{E} 3 / 4$ & 30 & $(21.1)$ & $46 \pm 7.6$ & $211 \pm 38.4$ & $152 \pm 98.7$ & 6 & $(20.0)^{\mathrm{a}}$ \\
$\mathrm{E} 2 / 3$ & 10 & $(7.0)$ & $43 \pm 4.6$ & $202 \pm 24.2$ & $127 \pm 55.7$ & 0 & \\
$\mathrm{E} 2 / 4$ & 3 & $(2.1)$ & $45 \pm 4.7$ & $233 \pm 16.3$ & $133 \pm 63.2$ & 1 & $(33.3)$ \\
$\mathrm{E} 4 / 4$ & 3 & $(2.1)$ & $47 \pm 5.4$ & $209 \pm 7.7$ & $135 \pm 47.9$ & 0 & \\
$\mathrm{E} 2 / 5$ & 1 & $(0.7)$ & 37 & 178 & 188 & 0 & \\
$\mathrm{E} 3 / 7$ & 1 & $(0.7)$ & 54 & 235 & 144 & 0 & \\
\hline
\end{tabular}

Values are mean $\pm \mathrm{SD}$. Ch, cholesterol; TG, triglyceride; $\mathrm{HCH}$, hypercholesterolemia (total serum cholesterol $>250 \mathrm{mg} / \mathrm{dl})$. ${ }^{2}$ Significant difference $(\mathrm{p}=0.023)$ as compared with $\mathrm{E} 3 / 3$.

terolemia was detected in five of the 94 subjects with the apo E3/3 phenotype $(5.3 \%)$ and six of the 30 subjects with the apo E3/4 phenotype $(20.0 \%)$. The difference was statistically significant $(\mathrm{p}=0.023)$. The mean $( \pm \mathrm{SD})$ serum total cholesterol levels were $198 \pm 29.6 \mathrm{mg} / \mathrm{dl}$ in the 94 subjects with the apo E3/3 phenotype and 
$211 \pm 38.4 \mathrm{mg} / \mathrm{dl}$ in the 30 subjects with the apo E3/4 phenotype. Although the difference was not quite significant at the $5 \%$ level $(t=1.92,0.05<\mathrm{p}<0.10)$, subjects with the apo E $3 / 4$ phenotype tended to have a higher serum cholesterol level than subjects with the apo $\mathrm{E} 3 / 3$ phenotype.

Table 2 shows the prevalence of hypercholesterolemia and mean serum total cholesterol levels in the apo E4-absent and apo E4-present subjects. Hypercholesterolemia was detected in five of 106 apo E4-absent subjects $(4.7 \%)$ and seven of 36 apo E4-present subjects $(19.4 \%)$. The difference was significant $(p=0.012)$. Furthermore, mean serum total cholesterol levels were significantly higher in the apo E4-present subjects than in the apo E4-absent subjects $(213 \pm 29.1$ versus $199 \pm 36.0$, $t=2.32, \mathrm{p}<0.05$ ). The individual data on serum lipid levels of the hypercholes-

Table 2. Prevalence of hypercholesterolemia and mean serum total cholesterol levels in the apo E4-absent males and apo E4-present males.

\begin{tabular}{lccccc}
\hline Apo E phenotype & $\mathrm{n}$ & $\begin{array}{c}\text { Age } \\
(\mathrm{mean} \pm \mathrm{SD})\end{array}$ & \multicolumn{1}{c}{ Hypercholesterolemia } & $\begin{array}{c}\text { Total } \\
\text { cholesterol } \\
(\mathrm{mean} \pm \mathrm{SD})\end{array}$ \\
\hline $\begin{array}{l}\mathrm{E} 4-\mathrm{m} \text {-absent } \\
(\mathrm{E} 3 / 3, \mathrm{~d} 1)\end{array}$
\end{tabular}

${ }^{\mathrm{a}}$ Significant difference $(\mathrm{p}=0.012)$. $\mathrm{b}$ Significant difference $(t=2.32, \mathrm{p}<0.05)$.

Table 3. Individual data on serum lipid levels in hypercholesterolemic subjects.

\begin{tabular}{rrrrrr} 
& & $\begin{array}{c}\text { Apo E } \\
\text { phenotypes }\end{array}$ & Total & HDL & $\begin{array}{c}\text { Total TG } \\
(\mathrm{mg} / \mathrm{dl})\end{array}$ \\
\hline HCD- 35 & 48 & E3/3 & 274 & 40 & 408 \\
94 & 55 & $3 / 3$ & 276 & 44 & 130 \\
97 & 44 & $3 / 3$ & 260 & 45 & 105 \\
313 & 54 & $3 / 3$ & 254 & 78 & 35 \\
343 & 44 & $3 / 3$ & 251 & 52 & 189 \\
\hline HCD- 15 & 52 & E3/4 & 265 & 45 & 169 \\
25 & 58 & $3 / 4$ & 264 & 64 & 82 \\
40 & 35 & $3 / 4$ & 255 & 42 & 192 \\
167 & 54 & $3 / 4$ & 291 & 90 & 53 \\
336 & 42 & $3 / 4$ & 257 & 66 & 119 \\
340 & 39 & $3 / 4$ & 274 & 55 & 157 \\
\hline HCD-319 & 48 & E2/4 & 256 & 46 & 212 \\
\hline
\end{tabular}


terolemic subjects are given in Table 3. In the case of hypercholesterolemic subjects with the apo E4, all individuals had moderate hypercholesterolemia with a normal triglyceride level or with mild hypertriglyceridemia.

\section{DISCUSSION}

As to the association of the apo E4 allele with hypercholesterolemia, Utermann et al. (1984) reported that apo E4 was significantly more frequent in patients with hypercholesterolemia than in blood donors in Federal Republic of Germany. Apo E4 was also significantly more frequent among male subjects with multifactorial hypercholesterolemia than among normocholesterolemic controls in Norway (Leren et al., 1985). It is well established that both the individual's genotype and nutritional factors are involved in determining serum total cholesterol levels. Since the apo E4 allele is present in about $20 \%$ of Japanese populations and since the apo E4 allele may act as one of polymeric genes in predisposing one to multifactorial hypercholesterolemia, it is important to investigate whether the apo E4 allele is associated with hypercholesterolemia in Japanese. An association of the apo E4 allele with hypercholesterolemia in Japanese, if present, would be more easily verified in subjects working in large cities than in agricultural districts, because mean serum total cholesterol levels in middle-aged Japanese are generally higher in large cities than in agricultural districts. This study has shown that the prevalence of hypercholesterolemia was significantly higher in the apo E4-present subjects than in the apo E4-absent subjects in apparently healthy male civil servants working in Tokyo. Furthermore, hypercholesterolemia was significantly more frequent among the apo E3/4 phenotype group than among the apo E3/3 phenotype. Considering that only the apo E3 allele has yet to be associated with any of the lipid disorders, these findings suggest that the apo E4 allele is associated with hypercholesterolemia at least in Japanese males working in large cities.

In the present study, it was observed that hypercholesterolemic subjects with the apo E4 had moderate hypercholesterolemia with a normal triglyceride level or. with mild hypertriglyceridemia. In addition, mean serum total cholesterol levels were significantly higher in the apo E4-present subjects than in the apo E4-absent subjects. Mean serum total cholesterol levels also tended to be higher in the apo E3/4 phenotype group than in the apo E3/3 phenotype group, though the difference was not quite significant at the $5 \%$ level probably due to small sample sizes. It has been demonstrated that mean serum total cholesterol levels have a tendency to be higher in the apo E3/4 phenotype as compared with the apo E3/3 phenotype in Caucasians (Sing and Davignon, 1985; Boerwinkle et al., 1987; Pagnan et al., 1987). Considering that most of multifactorial hypercholesterolemia is not severe and that many individuals with apo E4 are normocholesterolemic, these findings suggest that the apo $\mathrm{E} 4$ allele acts as a polymeric gene in predisposing one to hypercholesterolemia. The apo E4 molecule differs from the apo E3 molecule by an amino acid substitution 
from cysteine to arginine at residue 112 (Rall et al., 1982). The mechanism underlying the association of the apo E4 allele with hypercholesterolemia might be related to a phenomenon observed by Gregg et al. (1986) that apo E4 is catabolized more rapidly than apo $\mathrm{E} 3$.

Acknowledgments This investigation was supported by Scientific Research Grant from the Ministry of Education, Science and Culture, and a Research Grant for Intractable Diseases from the Ministry of Health and Welfare, Japan.

\section{REFERENCES}

Allain, C.C., Poon, L.S., Chan, F.C.S., Richmond, W., and Fu, C.P. $1974 . \quad$ Enzymatic determination of total serum cholesterol. Clin. Chem. 20: 470-475.

Armitage, P. 1977. Comparison of two means: Unpaired case. In Statistical Methods in Medical Research, 4th printing, Blackwell Scientific Publications, Oxford, pp. 116-126.

Asakawa, J., Takahashi, N., Rosenblum, B.B., and Neel, J.V. 1985. Two-dimensional gel studies of genetic variation in the plasma proteins of Amerindians and Japanese. Hum. Genet. 70: 222-230.

Assmann, G., Schmitz, G., Menzel, H.-J., and Schulte, H. 1984. Apolipoprotein E polymorphism and hypercholesterolemia. Clin. Chem. 30: 641-643.

Boerwinkle, E., Visvikis, S., Welsh, D., Steinmetz, J., Hanash, S.M., and Sing, C.F. 1987. The use of measured genotype information in the analysis of quantitative phenotypes in man. II. The role of the apolipoprotein $\mathrm{E}$ polymorphism in determining levels, variability, and covariability of cholesterol, betalipoprotein, and triglycerides in a sample of unrelated individuals. $A m . J$. Med. Genet. 27: 567-582.

Ehnholm, C., Mahley, R.W., Chappell, D.A., Weisgraber, K.H., Ludwig, E., and Witztum, J.L. 1984. Role of apolipoprotein $E$ in the lipolytic conversion of very low density lipoproteins to low density lipoproteins in type III hyperlipoproteinemia. Proc. Natl. Acad. Sci. USA 81: $5566-5570$.

Eto, M., Watanabe, K., and Ishii, K. 1986. A racial difference in apolipoprotein E allele frequencies between the Japanese and Caucasian populations. Clin. Genet. 30: 422-427.

Gregg, R.E., Zech, L.A.; Schaefer, E.J., Stark, D., Wilson, D., and Brewer, H.B., Jr. 1986. Abnormal in vivo metabolism of apolipoprotein $\mathrm{E} 4$ in humans. J. Clin. Invest. 78: 815-821.

Havel, R.J. 1982. Familial dysbetalipoproteinemia. New aspects of pathogenesis and diagnosis. Med. Clin. North. Am. 66: 441-454.

Kostner, G.M. 1976. Enzymatic determination of cholesterol in high-density lipoprotein fractions prepared by poly-anion precipitation. Clin. Chem. 22: 695.

Leren, T.P., Børrensen, A.-L., Berg, K., Hjermann, I., and Leren, P. 1985. Increased frequency of the apolipoprotein E-4 isoform in male subjects with multifactorial hypercholesterolemia. Clin. Genet. 27: 458-462.

Mahley, R.W. and Innerarity, T.L. 1983. Lipoprotein receptors and cholesterol homeostasis. Biochim. Biophys. Acta 737: 197-222.

Ordovas, J.M., Litwack-Klein, L., Wilson, P.W.F., Schaefer, M.M., and Scheafer, E.J. 1987. Apolipoprotein $\mathrm{E}$ isoform phenotyping methodology and population frequency with identification of apo E1 and apo E5 isoforms. J. Lipid Res. 28 : 371-380.

Pagnan, A., Zanetti, G., Bonanome, A., Biffanti, S., Ehnholm, C., and Keso, L. 1987. Apolipoprotein E polymorphism, serum lipids and occurrence of double pre-betalipoproteinemia (DPBL) in subjects from two different populations. Atherosclerosis $65: 23-28$. 
Rall, S.C., Jr., Weisgraber, K.H., and Mahley, R.W. 1982. Human apolipoprotein E. Complete amino acid sequence. J. Biol. Chem. 275: 4171-4175.

Sampson, E.J., Demers, L.M., and Krieg, A.F. 1975. Faster enzymatic procedure for serum triglycerides. Clin. Chem. 21: 1983-1985.

Shelburne, F.A. and Quarford, S.H. 1974. A new apolipoprotein of human plasma very low density lipoproteins. J. Biol. Chem. 249: 1428-1433.

Sing, C.F. and Davignon, J. 1985. Role of the apolipoprotein E polymorphism in determining normal plasma lipid and lipoprotein variation. Am. J. Hum. Genet. 37: 268-285.

Tsuchiya, S., Yamanouchi, Y., Onuki, M., Yamakawa, K., Miyazaki, T., Taya, T., Kondo, I., Ohnuki, M., and Hamaguchi, H. 1985. Frequencies of apolipoprotein E5 and E7 in Japanese. Jpn. J. Human Genet. 30: 271-278.

Tsuchiya, S., Yamanouchi, Y., Miyazaki, R., Onuki, M., Yamakawa, K., Kondo, I., Ohnuki, M., and Hamaguchi, H., 1986. Apolipoprotein E phenotypes and serum lipid levels in apparently healthy male adults in Tokyo. Jpn. J. Hum. Genet. 31: 15-20.

Utermann, G., Kindermann, I., Kaffarnik, H., and Steinmetz, A. 1984. Apolipoprotein E phenotypes and hyperlipidemia. Hum. Genet. 65: 232-236.

Weisgraber, K.H. and Mahley, R.W. 1978. Apoprotein (E-A-II) complex of human plasma lipoproteins. I. Characterization of this mixed disulfide and its identification in a high density lipoprotein subfraction. J. Biol. Chem. 253: 6281-6288.

Zannis, V.L., Breslow, J.L., and Utermann, G. 1982. Proposed nomenclature of apo E isoproteins. Apo E genotypes and phenotypes. J. Lipid. Res. 23: 911-914. 